\title{
Intra-arterial Thrombolysis for Retinal Artery Occlusion: The Calgary Experience
}

\author{
J.A. Pettersen, M.D. Hill, A.M. Demchuk, W. Morrish, M.E. Hudon, W. Hu, \\ J. Wong, P.A. Barber, A.M. Buchan
}

\begin{abstract}
Introduction: Retinal artery occlusion represents a medical emergency with poor prognosis for visual recovery. Spontaneous improvement is estimated to occur in less than $15 \%$ of central retinal artery occlusion (CRAO) cases and conventional treatments have provided only limited benefit. Intra-arterial thrombolysis has been reported as a potentially efficacious and safe treatment. Methods: We performed a retrospective chart review of all retinal artery occlusion cases treated with intra-arterial recombinant tissue-type plasminogen activator (rtPA) from January 1998 to May 2004. Patients received Goldmann perimetry visual field testing at a variable interval following the procedure (2 days-2.5 years). Visual acuity (VA) was re-assessed in May 2004. Results: Eight cases (59-77 years) were treated for CRAO, 6-18 hours post-onset with intra-arterial rtPA (10-20 mg over 15-60 minutes); one case of branch occlusion (BRAO) was treated with $30 \mathrm{mg}$ rtPA over 75 minutes, 12 hours post-onset. Among the six patients with CRAO assessed in clinic, three experienced improvement in VA by two or more gradations (Snellen lines); three improved by one gradation. However, none achieved a final VA better than 20/300. The case of branch occlusion improved to a VA of 20/20. All patients had residual monocular field defects. Conclusions: Our findings reveal a limited benefit for intra-arterial tPA compared to the rate of spontaneous improvement and conventional forms of therapy for retinal artery occlusion.
\end{abstract}

RÉSUMÉ: Thrombolyse intra-artérielle dans l'occlusion artérielle rétinienne: l'expérience de Calgary. Introduction: L'occlusion artérielle rétinienne constitue une urgence médicale dont le pronostic de récupération visuelle est mauvais. Une amélioration spontanée s'observe chez moins de $15 \%$ des cas d'occlusion de l'artère centrale de la rétine (OACR) et le traitement conventionnel est peu efficace. La thrombolyse intra-artérielle serait efficace et sûre. Méthodes: Nous avons effectué une révision rétrospective des dossiers de tous les patients ayant subi une occlusion d'artère rétinienne traitée par l'activateur du plasminogène tissulaire recombinant (rtPA) entre janvier 1998 et mai 2004. Le champ visuel des patients a été évalué par périmétrie de Goldmann à différents intervalles suite à la thrombolyse (2 jours à 2,5 ans). L'acuité visuelle (AV) a été réévaluée en mai 2004. Résultats: Huit patients, âgés de 59 à 77 ans, ont été traités pour une OACR entre 6 et 18 heures après le début des symptômes au moyen de rtPA intra-artériel (10 à $20 \mathrm{mg}$ sur une période de 15 à 60 minutes). Un cas d'occlusion d'une branche de cette artère (OBAR) a reçu 30 mg de rtPA sur une période de 75 minutes 12 heures après le début des symptômes. Trois de 6 patients ayant subi une OACR évaluée à la clinique ont eu une amélioration de leur AV de deux lignes de Snellen ou plus ; trois ont eu une amélioration d'une ligne. Cependant aucun n'a recouvré une AV finale meilleure que 20/300. Le cas d'OBAR a recouvré une AV de 20/20. Tous les patients avaient des déficits du champ visuel monoculaire résiduel. Conclusions: Chez nos patients, le bénéfice du traitement par le rtPA intra-artériel était limité comparé au taux d'amélioration spontanée et aux résultats du traitement conventionnel de l'occlusion artérielle rétinienne.

Can. J. Neurol. Sci. 2005; 32: 507-511

Retinal artery occlusion represents a medical emergency with a high risk for permanent blindness. Typical visual acuity (VA) levels on presentation range from light perception to 20/200 and spontaneous improvement is estimated to occur in less than $15 \%$ of central retinal artery occlusion (CRAO) cases. ${ }^{1}$ However, the prognosis is substantially better for branch occlusion (BRAO) with presenting VA varying from hand movements to better than $20 / 20,{ }^{2}$ and up to $80 \%$ of patients experiencing improvement of VA to $20 / 40$ or better but with residual monocular field defects. ${ }^{3}$ The goal of treatment has been to restore circulation before the ischemia becomes irreversible. While animal models have suggested that this critical time window is as short as 15 to 120 minutes with complete occlusion, ${ }^{4,5}$ clinical reports have demonstrated improvement in vision as late as three days postonset. ${ }^{6,7}$ This time discrepancy likely relates to the preservation of at least partial arterial flow in the vast majority of patients. ${ }^{7}$ Numerous conventional forms of treatment that have attempted

From the Departments of Clinical Neurosciences (JAP, MDH, AMD, JW, PAB), Radiology (WM, MEH, WH), Internal Medicine (MDH), Community Health Sciences University of Calgary (MDH), Calgary, AB, Canada; Department of Clinical Geratology, University of Oxford (AB), Oxford, England.

RECEIVED MARCH 7, 2005. ACCEPTED IN FINAL FORM JULY 25, 2005.

Reprint requests to: Jacqueline Pettersen, Department of Clinical Neurosciences, 12th floor, Foothills Medical Centre, 1403-29th St. NW, Calgary, Alberta, Canada T2N 2T9. 
to enhance retinal reperfusion include ocular massage, anterior chamber paracentesis, pentoxifylline, acetazolamide and carbogen (95\% oxygen, $5 \%$ carbon dioxide) inhalation. Unfortunately, none of these approaches have demonstrated a clear therapeutic benefit. ${ }^{8-10}$

Within the past 15 years, there have been several studies investigating the potential efficacy and safety of thrombolytic agents for the treatment of retinal artery occlusion. Most investigations have focused on intra-arterial, ${ }^{11-19}$ rather than intravenous, ${ }^{20,21}$ thrombolysis, citing an increased risk of hemorrhage and decreased efficacy as reasons not to further pursue the latter mode of delivery. This rationale was primarily based on early experience with coronary ${ }^{22}$ and ischemic stroke treatment, ${ }^{23}$ rather than direct experience using intravenous thrombolysis for CRAO.

Overall, results from published studies have suggested a benefit for intra-arterial retinal artery thrombolysis compared to conventional treatments or the natural history of retinal artery occlusion. However, all investigations to date have been nonrandomized, retrospective trials, and positive publication bias undoubtedly exists. Heterogeneity of trials including: (1) treatment times from four to 50 hours from onset; (2) various outcome measures; (3) use of urokinase or tPA, contributes to difficulties in interpreting results. A recent review ${ }^{24}$ summarized the visual outcome in 100 CRAO patients treated with intraarterial thrombolysis from 16 non-randomized, retrospective studies. A final VA of $20 / 40$ or better was experienced in $27 \%$ of eyes treated with intra-arterial thrombolysis. While potentially serious complications were observed in four patients, including transient hemiplegia and hypertensive crisis, none suffered a permanent neurological deficit.

We sought to examine the effectiveness and safety of intraarterial recombinant tissue-type plasminogen activator (rtPA) used for the treatment of retinal artery occlusion in our center by performing a retrospective review of all such cases.

\section{Methods}

We performed a retrospective chart review of all cases of retinal artery occlusion treated with intra-arterial rtPA over the seven year period from January 1998 to May 2004 at the Foothills Medical Centre in Calgary, Alberta. Information was collected on patient demographics, ischemic risk factors, side of retinal artery occlusion, fundoscopic findings, time from onset to treatment, dose and duration of rtPA given, and best-corrected VA at 24 hours. Patients received Goldmann kinetic full visual field testing at a variable interval following the procedure (2 days-2.5 years). Best-corrected final VA was assessed in May 2004.

\section{RESULTS}

Six men and three women between the ages of 43 and 77 years presented to the emergency department with sudden onset monocular visual loss affecting the left $(n=5)$ or right $(n=4)$ eye (see Table). Eight patients were determined to have CRAO based on extent of visual impairment and fundoscopic findings including any of: pale retina $(n=5)$, visible emboli $(n=1)$, ischemic macular edema $(n=3)$, cherry red spot $(n=3)$, boxcarring of retinal vessels $(n=1)$, reduced/absent retinal blood flow $(n=3)$. One patient (case 9) was determined to have a BRAO and had a visible embolus in the superior nasal and temporal retinal artery branches, pale retina and collapsed veins in the superior half of the retina. Cilioretinal arteries, which can help to maintain retinal perfusion during CRAO, were not identified in any of our patients. All cases were clinically consistent with a nonarteritic etiology. Known ischemic risk factors were common and consisted of hypertension $(n=4)$, elevated cholesterol levels $(n=5)$, coronary artery disease $(n=2)$, atrial fibrillation $(n=2)$, aortic stenosis $(n=1)$ and bicuspid aortic valve with previous episodes of transient monocular visual loss $(\mathrm{n}=1)$. Only one patient (case 7$)$ had no known cerebrovascular risk factors.

Table: Retinal Artery Occlusion Treated with rtPA

\begin{tabular}{|c|c|c|c|c|c|c|c|c|c|c|}
\hline Case & Age & Gender & Eye & $\begin{array}{l}\text { Time to } \\
\text { tPA (hr) }\end{array}$ & $\begin{array}{l}\text { tPA Dose } \\
\text { mg (min) }\end{array}$ & VA Baseline & VA 24 hrs & $\begin{array}{c}\text { VA Final } \\
\text { [Months since } \\
\text { tPA] }\end{array}$ & $\begin{array}{c}\text { VA Change } \\
\text { (Snellen lines) }\end{array}$ & $\begin{array}{l}\text { Subjective } \\
\text { Improvement }\end{array}$ \\
\hline 1 & 68 & $\mathbf{M}$ & os & 8 & $15(60)$ & HМ & $20 / 400$ & $20 / 400[33]$ & 2 & No \\
\hline 2 & 67 & $\mathbf{M}$ & OD & 9 & $15(15)$ & HM & CF & CF [31] & 1 & No \\
\hline 3 & 75 & $\mathbf{M}$ & OD & 18 & $10(60)$ & HM & CF & $20 / 300[25]$ & 2.5 & Yes (VFs) \\
\hline 4 & 59 & $\mathbf{F}$ & OS & 10 & $15(60)$ & HM & HM & CF [16] & 1 & Yes (VA) \\
\hline 5 & 71 & $\mathbf{F}$ & os & 8.5 & $12.5(50)$ & CF & CF & $20 / 400[13]$ & 1 & No \\
\hline 6 & 77 & $\mathbf{M}$ & OD & 8 & $10(30)$ & LP & $\mathbf{L P}$ & N/A & N/A & No \\
\hline 7 & 76 & $\mathbf{M}$ & OS & 6 & $15(45)$ & HM & HM & N/A & N/A & N/A \\
\hline 8 & 70 & $\mathbf{F}$ & os & 8 & $20(60)$ & $\mathbf{L P}$ & CF & CF [1] & 2 & Yes $(\mathrm{VF}+\mathrm{VA})$ \\
\hline $\begin{array}{c}9 \\
\text { BRAO } \\
\end{array}$ & 43 & $\mathbf{M}$ & OD & 12 & $30(75)$ & N/A & N/A & $20 / 20[55]$ & N/A & $\begin{array}{l}\text { Yes (VF + VA- } \\
\text { near-complete }\end{array}$ \\
\hline
\end{tabular}

OS: left eye; OD: right eye; LP: light perception; HM: hand movements; CF: counting fingers; N/A: information not available; VA: visual acuity; VF: visual field 


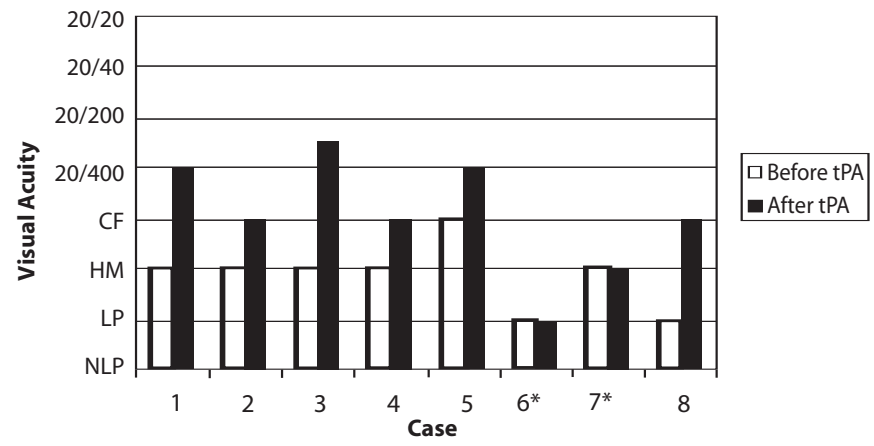

Figure 1: Visual acuity before treatment with intravenous rtPA and at final assessment in patients with CRAO. In two patients (cases 6 and 7), final assessments were not done. NLP: no light perception; LP: light perception; HM: hand movements; CF: counting fingers. *VA final assessment not done.

Six of the nine cases were initially assessed by an ophthalmologist with four receiving anterior chamber paracentesis (cases 1,2,4,5) and one case receiving ocular massage (case 8) prior to thrombolysis. None of the patients received fluorescein angiography. Recombinant tPA $(10-30 \mathrm{mg})$ was administered intra-arterially via a microcatheter in the proximal ophthalmic artery over a 15-75 minute period, 6-18 hours post-onset (see Table). No adverse reactions or complications were observed during or after treatment. Fundoscopic findings post-treatment were not consistently documented. At 24 hours post-treatment, VA was improved by two gradations (Snellen lines) in one patient and one gradation in three patients (see Table). On final assessment in May 2004, all six patients who were re-evaluated had experienced some improvement: three patients had improved by two or more VA gradations since baseline and three improved by one gradation (see Table and Figure 1). Interestingly, the patient with the greatest degree of improvement (case 3) had been diagnosed with macular degeneration in the other eye within a few weeks following treatment. No other ocular comorbidities such as glaucoma, cataracts, diabetic retinopathy, or other media opacities were present that may have accounted for poor recovery. Two patients did not return for final assessment and neither had experienced improvement at 24 hours. While baseline VA was uncertain in the patient with BRAO (case 9), VA was 20/20 at three months. All patients had residual monocular visual field defects which were consistent with retinal ischemic injury (see Figure 2). Two cases of CRAO (cases 3 and 8) reported subjective improvement and the one case of BRAO (case 9) reported almost complete resolution of an inferior visual field defect measured at two days post-treatment. One patient (case 6) did not undergo Goldmann perimeter visual field testing.

\section{DISCUSSION}

Intra-arterial rtPA for CRAO was associated with minimal improvements in visual acuity: three patients experienced at least two VA gradations of improvement. While this degree has been considered significant in previous reports, ${ }^{16,25}$ others have suggested at least three VA gradations of improvement ${ }^{7}$ or a final VA of 20/40 or better ${ }^{24}$ to be considered meaningful recovery. None of our CRAO patients experienced a final VA better than $20 / 300$. Further, four of the six cases with some noted improvement in VA (cases 1, 4, 5, and 8) and the patient with BRAO with subjective improvement (case 9) may have learned how to eccentrically fixate and thus compensate for their central blindness, rather than experience true recovery. Visual field impairments, regardless of VA changes, are also potentially debilitating. Without serial visual field testing, we cannot be sure if any of our patients experienced recovery in this regard. However, the marked degree of field impairments demonstrated on Goldmann perimetry testing at one month or more posttreatment in most patients (case 9 was the only patient tested within one month), suggests that recovery was minimal.

Potential explanations for the overall lack of effectiveness in the current study may relate to the absence of favorable predictive factors. Previously described predictors of good recovery have included, among other factors, the extent of the arterial obstruction, the presenting VA, the delay to beginning treatment, and the nature of the occluding material. Schmidt et a ${ }^{16}$ have described three stages of CRAO, corresponding to increasing degrees of obstruction: Stage I-incomplete CRAO, which is characterized by minimal or scarcely visible edema around the macula and a slight cherry red spot in the macula; Stage II-subtotal CRAO, which is a nearly complete CRAO; Stage III-CRAO with choroidal hypoperfusion (diagnosed by fluorescein angiography) or choroidal infarction. In those patients experiencing marked improvement in VA posttreatment, $82 \%$ had milder degrees of occlusion (Stages I and II), whereas none of the patients with poor recovery had incomplete (Stage I) occlusions. While it is difficult to retrospectively classify our cases, all had definite visible signs of CRAO, corresponding to at least Stage II occlusion.
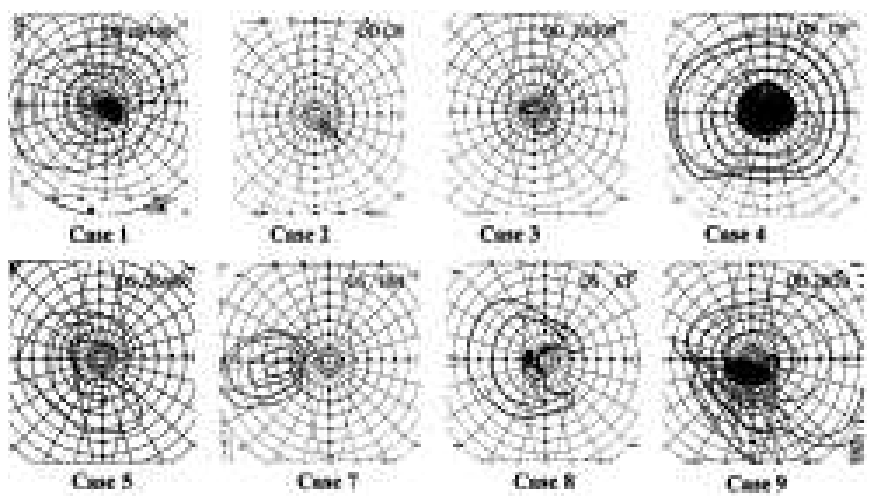

Figure 2: Goldmann visual fields in eight patients with retinal artery occlusion following treatment with rtPA. Perimetry was not performed in Case 6. Case 1: Central scotoma with inferior nasal defect; Case 2: Near-complete blindness with only patchy perception of V4e target in inferior temporal quadrant; Case 3: Loss of field except for central island of preserved vision; Case 4: Large central scotoma and depression of superior field; Case 5: Loss of central vision and nasal field with depression of remaining field; Case 7: Loss of field except for temporal island of vision; Case 8: Loss of central and nasal field and depression of remaining field; Case 9: Inferior altitudinal defect with large arcuate scotoma. 
The VA at presentation is another important predictor of prognosis: Those patients only able to perceive hand movements or count fingers, as in our study, tend to do much worse than those with better initial acuities. ${ }^{12,24}$ Another important and related factor is the time delay to the initiation of treatment. Several previous reports have described a negative correlation between prognosis and time to treatment, with better visual recovery observed in patients treated within six hours. ${ }^{11,12,14}$ None of our patients received intra-arterial treatment in less than six hours from the time of symptom-onset.

Finally, the nature of the occluding material may have prognostic significance, particularly with respect to its response to thrombolytic therapy. The commonest mechanism is thought to be embolic from the carotid arteries or from the heart rather than local thrombus formation. ${ }^{25}$ According to Arruga and colleagues, ${ }^{26}$ these emboli are composed of cholesterol in $74 \%$, calcified material in $10.5 \%$, and platelet fibrin in only $15.5 \%$ of cases. While some have speculated that there is no scientific rationale for using thrombolytic agents for calcified or cholesterol thrombi (i.e., $85.5 \%$ of cases), ${ }^{25}$ others have posited that the stasis-induced formation of secondary thrombi play an important role in the progression of arterial occlusions and that thrombolysis of these secondary emboli would be beneficial. ${ }^{15} \mathrm{In}$ the present study, only two cases were noted to have visible emboli on fundoscopic exam (cases 6 and 9) and their composition was unclear. In the patient with BRAO (case 9), the occluding material was thought to represent a calcific embolus, consistent with a presumed cardiac valvular source. On posttreatment fundoscopy, it was noted that there was some reduction in the size of the embolus.

Intra-arterial treatment of CRAO is technically challenging and is not successfully performed in all cases. Severe carotid artery stenosis or vessel tortuosity may prohibit arterial catheterization in otherwise eligible candidates. In addition, the vascular anatomy precludes superselective infusion of thrombolytic agents into the central retinal artery, and instead, delivery must occur more regionally in the ophthalmic artery. The central retinal artery is rarely visualized on catheter angiogram so the interventionalist or neurosurgeon performing the procedure has no direct feedback regarding the effectiveness of therapy. Intra-arterial therapy can only be offered in tertiary centers where facilities and expertise exist. Further, intra-arterial thrombolytic therapy has potential complications including ischemic stroke, intracranial hemorrhage, retroperitoneal hemorrhage and groin hematoma.

One alternative to intra-arterial therapy is to use intravenous thrombolytic agents. In two recent case series of intravenous tPA, 7 of $12(58 \%)$ patients experienced between three and eight VA gradations of improvement ${ }^{20}$ and at least three VA gradations of improvement were achieved by all three patients in another study. ${ }^{21}$ No complications occurred in either case series. While thrombolytic agents have not been used in conjunction with transcranial Doppler ultrasound (TCD) for CRAO, the recent CLOTBUST trial ${ }^{27}$ which demonstrated significant augmentation of t-PA-induced cerebral arterial recanalization with TCD, is suggestive of an intriguing treatment possibility. Another alternative would be to consider the use of the platelet GPIIbIIIa antagonists, although no reports of such treatment have been published.
Central retinal artery occlusion is potentially treatable medically. Outcomes should focus on restoration of functional vision, such as achieving a visual acuity of 20/40 or better and minimization of visual field defects. Despite other literature, our experience with intra-arterial therapy, although somewhat limited, has not been convincing for a role in the treatment of CRAO. Given the intensive resource use, technical difficulty of the procedure, and lack of effectiveness in our patient population, we will not continue to offer this therapy. Other options, such as intravenous drug administration (with or without TCD augmentation) may potentially be of benefit and should be studied further. A multi-center prospective study with defined entry criteria and outcome measures that compares thrombolytic (intra-arterial or intravenous) with conventional forms of treatment appears warranted to establish if a therapeutic option truly exists.

\section{ACKNOWLEDGEMENTS}

The authors thank the Heart and Stroke Foundation of Alberta and the Canadian Institute of Health Research for their support. We thank Rosalind Mullins for her involvement in the preliminary literature search and Dr. William Fletcher for his comments on the visual field descriptions.

\section{REFERENCES}

1. Atebara N, Brown GC, Cater J. Efficacy of anterior chamber paracentesis and carbogen in treating acute nonarteritic central retinal artery occlusion. Ophthalmology 1995;102:2029-2035.

2. Ros M, Magargal LE, Uram M. Branch retinal-artery obstruction: a review of 201 eyes. Ann Ophthalmol 1989;21:103-107.

3. Brown G, Magargal, LE, Shields, JA, Goldberg, RE, Walsh, PN. Retinal arterial obstruction in children and young adults. Ophthalmology 1981;88:18-25.

4. Hayreh S, Weingeist TA. Experimental occlusion of the central artery of the retina: retinal tolerance time to acute ischaemia. $\mathrm{Br}$ J Ophthalmol 1980;64:818-825.

5. Hayreh S, Kolder HE, Weingeist TA. Central retinal artery occlusion and retinal tolerance time. Ophthalmology 1980;87:75-78.

6. Duker J, Brown GC. Recovery following acute obstruction of the retinal and choroidal circulations: a case history. Retina 1988;8:257-260.

7. Augsburger J, Magargal LE. Visual prognosis following treatment of acute central retinal artery obstruction. Br J Ophthalmol 1980;64:913-917.

8. Beatty $\mathrm{S}$, Au Eong KG. Acute occlusion of the retinal arteries: Current concepts and recent advances in diagnosis and management. J Accid Emerg Med 2000;17:324-329.

9. Fraser S, Siriwardena D. Interventions for acute non-arteritic central retinal artery occlusion. Cochrane Database Syst Rev 2003;1.

10. Mueller A, Neubauer AS, Schaller U, Kamprik A. Evaluation of minimally invasive therapies and rationale for a prospective randomized trial to evaluate selective intra-arterial lysis for clinically complete central retinal artery occlusion. Arch Ophthalmol 2003;121:1377-1381.

11. Schmidt D, Schumacher M, Wakhloo AK. Microcatheter urokinase infusion in central retinal artery occlusion. Am J Ophthalmol 1992;113:429-434.

12. Schumacher M, Schmidt D, Wakhloo AK. Intra-arterial fibrinolytic therapy in central retinal artery occlusion. Neuroradiology 1993;35:600-605.

13. Wirostko W, Pulido, JS, Hendrix, LE. Selective thrombolysis of central retinal artery occlusion without long-term systemic heparinization. Surg Neurol 1998;50:408-410.

14. Weber J, Remonda L, Mattle H, Koerner U, et al. Selective intraarterial fibrinolysis of acute central retinal artery occlusion. Stroke 1998;29: 2076-2079. 
15. Richard G, Lerche R, Knospe V, Zeumer H. Treatment of retinal arterial occlusion with local fibrinolysis using recombinant tissue plasminogen activator. Ophthalmology 1999;106:768-773.

16. Schmidt D, Schumacher M. Stage-dependent efficacy of intraarterial fibrinolysis in central retinal artery occlusion (CRAO). Neuro-ophthalmology 1998;20:125-141.

17. Padolecchia R, Puglioli M, Ragone MC, Romani A, Collavoli PL. Superselective intraarterial fibrinolysis in central retinal artery occlusion. Am J Neuroradiol 1999;20:565-567.

18. Schmidt D, Schulte-Monting J, Schumacher M. Prognosis of central retinal artery occlusion: Local intraarterial fibrinolysis versus conservative treatment. Am J Neuroradiol 2002;23:1301-1307.

19. Arnold M, Koerner U, Remonda L, et al. Comparison of intraarterial thrombolysis with conventional treatment in patients with acute central retinal artery occlusion. J Neurol Neurosurg Psychiatry 2005;76:196-199.

20. Kattah J, Wang DZ, Reddy C. Intravenous recombinant tissue-type plasminogen activator thrombolysis in treatment of central retinal artery occlusion. Arch Ophthalmol 2002;120:1234-1236.
21. Mames R, Shugar JK, Levy L, Brasington A, Margo, CE. Peripheral thrombolytic therapy for central retinal artery occlusion. Arch Ophthalmol 1995;113:1094.

22. Kase C, O'Neal AM, Fisher M, Girgis GN, Ordia JL. Intracranial hemorrhage after use of tissue plasminogen activator for coronary thrombolysis. Ann Intern Med 1990;112:17-21.

23. Brott T, Broderick J, Kothari R. Thrombolytic therapy for stroke. Curr Opin Neurol 1994;7:25-35.

24. Beatty S, Au Eong KG. Local intra-arterial fibrinolysis for acute occlusion of the central retinal artery: A meta-analysis of the published data. Br J Ophthalmol 2000;84:914-916.

25. Hayreh S. Retinal arterial occlusion with LIF using rtPA. [Letter to the editor]. Ophthalmology 1999;106(7):1236-1239.

26. Arruga J SM. Ophthalmologic findings in 70 patients with evidence of retinal embolism. Ophthalmology 1982;89:1336-1347.

27. Alexandrov A, Molina CA, Grotta JC, et al. Ultrasound-enhanced systemic thrombolysis for acute ischemic stroke. N Engl J Med 2004;351:2170-2178. 